\title{
State Paralysis: The Impacts of Procurement Risk on Government Effectiveness
}

\author{
Pre-analysis Plan
}

\begin{abstract}
Public procurement plays a key role in allocating limited budgetary resources to public service delivery in countries with a functional rule of law. This project studies a puziling phenomenon: in developing countries like Brazil, substantive shares of the federal and sub-national budgets are not spent despite clear needs for additional resources to improve the quality of public services or to fund emergency spending in contexts of crisis. In line with a growing literature that documents the potential unintended effects of the enforcement of rules on bureaucratic performance, we investigate the role of procurement risk - when passive waste is misinterpreted as active waste - as a driver of unspent public funds by Brazilian municipal governments. Randomizing interventions that decrease procurement risk or that make it less salient within a sample of municipal health secretariats, we investigate its effects on budget execution and health outputs and outcomes, in the context of the COVID-19 pandemic.
\end{abstract}

\section{Introduction}

Decentralization typically goes hand-in-hand with the introduction of strict regulatory rules by the federal government in an attempt to limit moral hazard by the local bureaucracy. However, there is increasing evidence that such mechanisms often focus too narrowly on avoiding wrongdoing rather than promoting high quality spending, generating incentives that can ultimately hurt the ability of local governments to provide local goods and services. In Brazil, the country of our study, even in the context of the COVID19 crisis, less than $30 \%$ of emergency federal funds had been spent many months after approval. ${ }^{1}$ In local governments, where state capacity is lower, this problem pre-dates the current crisis.

A growing literature documents the effects of the strict enforcement of rules on bureaucratic performance. ${ }^{2}$ In this project, we investigate the role of procurement risk as a driver of under-spending of existing funds by local governments in Brazil. A key mechanism for why external monitoring might hurt public service delivery is procurement risk: when passive waste is misinterpreted as active waste (Bandiera, Prat and Valetti, 2009), bureaucrats might decide that procuring goods and services is not worthwhile. This can deteriorate the quality of public service delivery, hurting downstream outcomes - particularly in the

\footnotetext{
1 See https://valor.globo.com/brasil/noticia/2020/06/17/na-saude-governo-gasta-so-28-do-total-autorizado-para-despesasemergenciais.ghtml, accessed on June 24, 2020

2 Avis, Ferraz and Finan (2018) document that random audits by the Office of the Comptroller General decrease corruption among Brazilian municipalities. Lichand and Fernandes (2019) finds that an anti-corruption program based on federal audits to Brazilian municipalities drastically decrease local spending; Gerardino et al. (2019) finds that public officials avoid procurement processes that are more regulated in response to audits; Bertrand et al. (2017) find negative effects of distorted incentives from bureaucratic rigidity on downstream outcomes - quite substantial in terms of GDP growth -; and Rasul and Rogger (2017) and Shin (2008) find that similar inefficiencies arise out of monitoring bureaucratic performance.
} 
context of a crisis like covid-19. Evidence on this mechanism is, however, difficult to generate, as the incidence of external monitoring (e.g. the probability of being audited) is not randomly assigned. What is more, experimentally varying the probability of monitoring by changing legislation would be politically complex and involves high costs.

To deal with those challenges, this study introduces exogenous variation in procurement risk by randomly assigning a simple intervention to support local bureaucrats in complying with procurement regulations: a tutorial to guide local bureaucrats in using templates for public procurement documents (from terms of reference to auction procedures), provided by the Brazilian federal government to support municipalities in the context of COVID-19. While those templates were made available to all municipalities, our hypothesis is that most have not effectively put them to use, precisely because they lack the high-capacity personnel to ensure compliance with the complex procurement requirements such documents allude to. The intervention (the tutorial) has the potential to not only shed light on this mechanism, but also to provide a simple and cost-effective policy tool to help mitigate adverse effects of external enforcement on public service delivery, particularly in this time of crisis.

To disentangle the effects of information from those of salience (along the lines of Bettinger et al., 2020), since tutorials might induce local bureaucrats to worry about procurement risk to a lesser extent regardless of their informational content, the experiment also randomizes a salience intervention: an alternative tutorial to take local bureaucrats through a recent decision by a Brazilian Supreme Court Justice, which determined that bureaucrats cannot be punished by 'honest mistakes' in their attempts to manage the COVID-19 crisis. While the intervention provides no guidance in handling procurement risk, it could presumably mitigate the effects of the latter on budget execution and public service delivery.

The project addresses the following research questions:

1. Do interventions to support local bureaucrats undertake compliant competitive procurement procedures in the context of COVID-19 decrease their perceived risk of incurring in procedural mistakes that could be framed as wrongdoing?

2. Do such interventions increase planned spending, delivery rates and payment rates within health transfers?

3. Do they improve public service delivery, measured by health outputs and outcomes?

4. Do they have spillover effects on health spending out of own resources? Do they have spillover effects on budget execution and outcomes outside of health, such as in education?

5. What share of those effects is driven by salience? 


\section{Intervention and experimental design}

The experiment will be implemented in collaboration CONASEMS ${ }^{3}$, the Brazilian Council of Municipal Health Secretaries. It will take place during the month of August/2020, when municipal health secretaries and other local policymakers will receive a short online questionnaire about their experiences in the context of the COVID-19 response, particularly when it comes to their main challenges for budget execution and public service delivery during the pandemic.

\section{Intervention}

Immediately after the survey questions, respondents will be randomly assigned to 3 groups.

Group 1 (Information). The first group will be shown a video tutorial on how to use the templates for procurement documents elaborated by Brazilian Attorney General's Office (Advocacia Geral da União, AGU). We will also highlight that some of the strictest State Courts of Accounts have endorsed those templates.

Group 2 (Salience). The second group will be shown a video tutorial about a Supreme Court decision clarifying that only 'grotesque' misconducts by public managers in the context of COVID-19 would be subject to legal action.

Group 3 (Control). The third group will be shown a video tutorial on Sanitary and Health Law reports elaborated by the Brazilian National Council of Health Secretaries (CONASS) and made available on the CONASEMS website - completely unrelated to procurement.

All tutorials share a symmetric structure and very similar lengths, and showcase websites where participants can find all relevant information about the object of the tutorial they have been assigned to. We will measure take-up and usage of the tutorials and templates through questions following the intervention and in a follow-up wave, planned to take place one month after the baseline.

CONASEMS has access to the universe of municipal health secretariats $(5,570)$, which we take as our sampling frame. The survey will be distributed through CONASEMS supporters' network, 216 staff members (often former municipal health secretariats) who help coordinate CONASEMS's engagement with the health secretariats. The network is a partition of all secretariats, based on geographical proximity, with each supporter responsible for reaching out to a unique subset of health secretariats.

We expect take-up rates around 50\% -- based on the previous experience of CONASEMS with online surveys. We do not pre-assign municipalities to treatment conditions; rather, randomization will be done on the spot, stratified by State (because of heterogeneous external enforcement by each State Court of

\footnotetext{
${ }^{3}$ https://www.conasems.org.br/
} 
Accounts) and by quartile of budget leftovers from federal transfers (as a fraction of total health transfers to the municipality) as of December/2019 (our measure of budget execution at baseline). The intervention is scheduled to be rolled out on the first week of August.

Table 1: Randomization strategy

\begin{tabular}{|c|c|c|}
\hline Information & Salience & Control \\
\hline $1 / 3$ municipalities & $1 / 3$ municipalities & $1 / 3$ municipalities \\
\hline
\end{tabular}

Table 1 above summarizes the randomization strategy for the intervention: within the universe of 5,570 municipal health secretaries to whom the online questionnaire will be sent, a third is expected to be assigned to each treatment arm. There might be slight deviations from those fractions based on the number of municipalities who eventually take up the survey within each stratum.

\section{Outcomes}

Our baseline data will comprise survey answers by municipal health secretaries about perceived procurement risk, main challenges in budget execution and public service delivery in the context of COVID-19, captured by five questions asked before the intervention. Additionally, right after the interventions, participants will be requested to list a high-official in the municipality to receive further materials about the topic of the tutorial, and asked whether s/he would undertake a costly action (in terms of opportunity costs of time) to connect with other public managers on the topic of the tutorial, by informing all time slots they would be available to meet (in a structure meant to emulate a BDM elicitation procedure). Last, the survey has two optional questions at the end about the allocation of federal transfers to fight COVID-19 and the main difficulties linked to budget execution of those funds. Since those questions are after the intervention, they would allow to test for treatment effects on perceived risks, and to elicit experiment demand effects on previous budget allocations.

The follow-up dataset will repeat the 5 initial questions, and ask specifically about the usage of the templates provided by the Brazilian Attorney General's Office.

Besides survey data, we have access to monthly data on federal transfers and respective budget leftovers for all municipalities, from CONASEMS. For health budget execution we have quarterly data from SIOPS (the federal system that monitors expenditures of the National Health System). For other, more detailed budget execution metrics (such as planned spending, delivery rates and payment rates, funded by both transfers and municipalities' own budget), we will try to get access to quarterly data for the States of Ceará, Maranhão, Minas Gerais, Pernambuco, Piauí, Rio Grande do Norte, Rio Grande do Sul, Rio de Janeiro, Sao Paulo and Tocantins (based on contract-level data). 
When it comes to health outputs and outcomes, we have monthly data from DATASUS for all municipalities. For other outcomes, such as education, we will investigate dropout rates (School Census in March/21) and standardized test scores (Prova Brasil in November/21). It is possible, nonetheless, we will not find impacts on those, as our intervention is in the early stage of public procurement. Other bottlenecks in execution and payment may prevent budget execution from increasing to a greater extent, or other constraints to quality spending might prevent higher execution from translating into improved public service delivery.

Power calculations indicate that, under a 50\% take-up rate of the online survey (in line with CONASEMS's prior experience), we could detect treatment effects of at least 1.46 percentage points on municipalities' planning rate (1.69 percentage points differences between the information and salience groups), based on the sample variance for that outcome computed from Lichand and Fernandes (2020); and of at least 0.09 standard deviation on standardized health outputs and outcomes ( 0.11 differences between the information and salience groups).

As treatment effects might take some time to kick in (or, alternatively, fade out over time), we will also estimate dynamic treatment effects, interacting the treatment indicators with months elapsed since exposure. Other potential refinements include exploring heterogeneous treatment effects based on variation in the extent of control enforcement by different State Courts of Accounts, on baseline budget execution rates, and on whether municipalities are part of consortia that centralize public procurement procedures. We also plan on using survey answers as source of heterogeneity, for instance if an official reported apprehension regarding procurement risk, we expect treatment to be more effective vis-a-vis an official who declared having other concerns.

\section{Empirical analysis}

Since the intervention is randomly assigned, comparing outcomes across the Information, Salience and the control groups yields causal treatment effects on the outcomes of interest (Section III). Using ordinary least squares regressions, we will estimate:

$$
Y_{i k s}^{j}=\beta_{0}+\beta_{1} \operatorname{Inf}_{i}+\beta_{2} \operatorname{Sal}_{i}+\lambda X_{i k s}+\theta_{k}+\theta_{s}+u_{i}
$$

Where:

- $\quad Y_{i k s}^{j}$ : Outcome variable $\mathrm{j}$ for municipality i coordinated by supporter $\mathrm{k}$ in stratum s;

- $\quad \operatorname{Inf}_{i}$ : Indicator variable equal to 1 if municipality $i$ is assigned to information treatment, 0 otherwise;

- $S a l_{i}$ : Indicator variable equal to 1 if municipality $\mathrm{i}$ is assigned to salience treatment, 0 otherwise;

- $X_{i k s}$ : municipal-level controls 
- $\theta_{s}$ : stratum fixed-effects.

For outcomes measured both at baseline and at the follow-up wave, we can estimate

$$
Y_{i k s t}^{j}=\beta_{0}+\beta_{1} I n f_{i t}+\beta_{2} \operatorname{Sal}_{i t}+\theta_{i}+u_{i t}
$$

Where:

- $Y_{i k s t}^{j}$ : Survey answer $\mathrm{j}$ by municipality $\mathrm{i}$ coordinated by supporter $\mathrm{k}$ in stratum $\mathrm{s}$ at time $\mathrm{t} \in\{0,1\}$;

- Inf $f_{i t}$ : Indicator variable equal to 1 if municipality $\mathrm{i}$ is assigned to information treatment at $\mathrm{t}=1,0$ otherwise;

- Sal $_{i t}$ : Indicator variable equal to 1 if municipality $\mathrm{i}$ is assigned to salience treatment at $\mathrm{t}=1,0$ otherwise;

- $\theta_{i}$ : municipality fixed-effects.

In all regressions, we will cluster standard-errors at the municipality level. We are interested in testing $\beta_{1}=$ $0, \beta_{2}=0$ and $\beta_{1}=\beta_{2}$. 


\section{REFERENCES}

Avis, E., C. Ferraz and F. Finan (2018) "Do Government Audits Reduce Corruption? Estimating the Impacts of Exposing Corrupt Politicians," Journal of Political Economy, 126(5), 1912-1964.

Bandiera, O., A. Prat, and T. Valetti (2009). “Active and Passive Waste in Government Spending: Evidence from a Policy Experiment," The American Economic Review, 99(4), pp. 1278-1308.

Bertrand, M., R. Burgess, A. Chawla, and G. Xuo (2017). "The Costs of Bureaucratic Rigidity: Evidence from the Indian Administrative Service," http://www.lse.ac.uk/economics/Assets/Documents/personalpages/robin-burgess/ costs-of-bureaucratic-rigidity.pdf.

Bettinger, E., Cunha, N., Lichand, G., \& Madeira, R. (2020). “Are Effects of Informational Interventions Driven by Salience?," ECON - Working Papers 350, Department of Economics - University of Zurich.

Gerardino, M.P., Litschig, S. and Pomeranz, D., (2017). "Can audits backfire? Evidence from public procurement in Chile," National Bureau of Economic Research Working Paper No. 23978.

Lichand, G., and G. Fernandes (2019). "The Dark Side of the Contract: Do Government Audits Reduce Corruption in the Presence of Displacement by Vendors?," mimeo.

Rasul, I., and D. Rogger (2018). "Management of Bureaucrats and Public Service Delivery: Evidence from the Nigerian Civil Service," The Economic Journal, 128(608), pp. 413-446.;

Shi, L. (2008) “The Limit of Oversight in Policing: Evidence from the 2001 Cincinnati Riot," Journal of Public Economics, 93(1-2), pp. 99-113. 